\title{
Pharmacokinetics, Tolerability and Pharmacogenetics of DA-803I After Multiple Ascending Doses in Healthy Male Subjects
}

\author{
Sejung Hwang (D) \\ Dae Young Lee ${ }^{2}$ \\ Joo-Youn Cho (1D) ${ }^{1,3}$ \\ Jae-Yong Chung ${ }^{4}$ \\ In-Jin Jang (D' \\ Kyung-Sang Yu (D) ${ }^{1,3}$ \\ SeungHwan Lee (D) \\ 'Department of Clinical Pharmacology \\ and Therapeutics, Seoul National \\ University College of Medicine and \\ Hospital, Seoul, Republic of Korea; ${ }^{2}$ Drug \\ Metabolism and Pharmacokinetics \\ (DMPK), Drug Evaluation, Dong-A ST \\ Research Institute, Gyonggi-do, Republic \\ of Korea; ${ }^{3}$ Department of Biomedical \\ Sciences, Seoul National University \\ College of Medicine, Seoul, Republic of \\ Korea; ${ }^{4}$ Department of Clinical \\ Pharmacology and Therapeutics, Seoul \\ National University College of Medicine \\ and Bundang Hospital, Seongnam, \\ Republic of Korea
}

Purpose: DA-8031 is a novel selective serotonin reuptake inhibitor for the treatment of premature ejaculation. This study investigated the pharmacokinetics, safety and tolerability of multiple oral doses of DA-8031. In addition, a genetic analysis was explored to evaluate the effect of genetic polymorphisms on the pharmacokinetics of DA-8031.

Subjects and Methods: A dose block-randomized, double-blind, placebo-controlled study was conducted in 3 dose groups with 20,30 and $40 \mathrm{mg}$ of DA-8031. Healthy male subjects were randomized to DA-8031 or placebo at a 4:1 ratio in each dose group of 10 subjects by oral administration once daily for 7 consecutive days. Serial blood and urine samples were collected for the pharmacokinetic evaluation, and the pharmacokinetic-related genes were analyzed by $\mathrm{DMET}^{\mathrm{TM}}$ plus. A safety evaluation was conducted including adverse events (AEs) monitoring and 12-lead electrocardiogram (ECG).

Results: The plasma DA-8031 concentration reached the maximum concentration $\left(\mathrm{C}_{\max }\right)$ in 2.2 to $3.0 \mathrm{~h}$ and was eliminated with a mean half-life of 25.5 to $26.7 \mathrm{~h}$ at steady state. The accumulation index of DA-8031 ranged 2.3 to 2.8. The systemic exposure of DA-8031 of the CYP2D6 intermediate metabolizer (IM) was significantly higher compared to the CYP2D6 poor metabolizer (PM). There were no clinically significant QTc interval changes, and all the adverse events were mild.

Conclusion: After multiple oral doses of DA-8031 20, 30, and $40 \mathrm{mg}$ in this study, the systemic exposure of DA-8031 increased in a more than dose-proportional manner with the increasing doses, and DA-8031 was generally well tolerated. In addition, the genetic polymorphisms of CYP2D6 have an impact on the pharmacokinetics of DA-8031.

Keywords: selective serotonin reuptake inhibitors, clinical pharmacology, phase 1 study, pharmacogenomics

\section{Introduction}

Premature ejaculation (PE) is one of the common male sexual dysfunctions, and its prevalence rate is globally $20-30 \%$ and $11-33 \%$ in Korea. ${ }^{1,2}$ Although the etiologies of PE are not fully understood, psychological factors such as the anxiety for rapid ejaculation ${ }^{1}$ or neurobiological factors associated with the hyposensitivity of 5-hydroxytryptamine (5-HT) $2 \mathrm{C}$ and the hypersensitivity of $5-\mathrm{HT}_{1 \mathrm{~A}}$ receptors are thought to contribute to the pathophysiology of PE. ${ }^{1,3,4}$

So far, there are two approaches in the treatment of PE based on the etiologies: One is behavioral/psychotherapy, and the other is pharmacotherapy. ${ }^{1}$ Off-label and on-demand selective serotonin reuptake inhibitors (SSRIs) and tricyclic
Correspondence: SeungHwan Lee Department of Clinical Pharmacology and Therapeutics, Seoul National University College of Medicine and Hospital, I0I

Daehak-ro, Jongno-gu, Seoul, 03080,

Republic of Korea

Tel +82-2-2072-2343

Fax $+82-2-2072-0720$

Email leejh4I3@snu.ac.kr 
antidepressants (TCAs) are commonly used for PE. ${ }^{1}$ SSRIs and TCAs are approved by and commonly used for the treatment of mood disorders and anxiety. ${ }^{5,6}$ SSRIs including fluoxetine, paroxetine and sertraline are used as an off-label drug for the treatment of PE, and SSRIs are thought to increase the latency by inhibiting serotonin transporters that reabsorb 5-HT from the nerve terminal. ${ }^{7}$ Recently, dapoxetine (Johnson \& Johnson, Priligy, New Brunswick, NJ, USA) got marketing approval in some countries including Europe for the treatment of PE as a short-acting SSRI used in an on-demand manner., ${ }^{8,9}$ However, dapoxetine showed a high prevalence of discontinuation in a clinical trial, ${ }^{10}$ and on-demand SSRIs might be an inappropriate approach for lifelong PE and have limited effects compared to daily SSRIs. ${ }^{11,12}$ On the other hand, the daily SSRI treatments currently used increase the risk of adverse effects such as headache, nausea, diarrhea and sexual dysfunctions (reduced libido and erectile dysfunctions) ${ }^{4,7,9,11,13}$ due to the potential drug-drug interactions and another serotonin sub-receptor and neurotransmitter receptor selectivity. ${ }^{4,11,14}$ Thus, a novel SSRI is needed to overcome these current defects of on-demand and daily SSRIs.

DA-8031 is a novel SSRI for the treatment of PE. ${ }^{15,16}$ In a preclinical study in rats, DA-8031 delayed the latency to ejaculation. ${ }^{15}$ In a first-in-human single ascending dose clinical study, DA-8031 was rapidly absorbed at a median time of 2-3 h and eliminated with a mean terminal $t_{1 / 2}$ of 17.9-28.7 h with a dose range of 5-120 mg. Although QT prolongation was observed after a single dose of $120 \mathrm{mg}$, DA-8031 was well tolerated after single doses of $80 \mathrm{mg}$ or less. $^{16}$

With regards to the chemical structure and metabolites of DA-8031, the previous in vitro study revealed that the chemical structure of DA-8031 and DA-8031 metabolized to M2, M4 and M1, and then M4 and M1 metabolized to $\mathrm{M} 5 .{ }^{16} \mathrm{In}$ addition, the in-vitro study also revealed that five cytochrome-P450 enzymes (CYPs) (CYP2C19, CYP2C8, CYP2D6, CYP3A4 and CYP3A5) were involved in the metabolism pathway of DA-8031. In the first-in-human single ascending dose clinical study, the metabolic ratios of M4 and M5 were higher than those of M1 and M2. This previous study also showed that the exposure of DA-8031 and the metabolic ratios of the metabolites (M1, M4, and M5) were different according to the genetic polymorphism of CYP2D6, extensive and intermediate metabolizer. This result suggested that CYP2D6 is involved in the pathway for the formation of M1, M4 and M5. Otherwise, the genetic variability of CYP2C19 had a limited effect on the metabolism of M1. ${ }^{16}$

The aim of this study was to investigate the pharmacokinetics, safety, and tolerability after multiple ascending oral doses of DA-8031. In addition, it evaluated the effect of genetic polymorphisms of drug metabolizing enzymes on the pharmacokinetics of DA- 8031 .

\section{Methods}

The clinical trial was approved by the Institutional Review Board (IRB) at Seoul National University Hospital and conducted in accordance with the Declaration of Helsinki and Korean Good Clinical Practice (KGCP) (ClinicalTrials.gov identifier: NCT01104948, IRB number: 1002-068-310). Written informed consents were obtained from all subjects prior to clinical study related procedures.

\section{Study Population}

Healthy Korean male subjects aged $20-45$ years with a body weight ranging from 60 to $90 \mathrm{~kg}$, and a body mass index (BMI) ranging from 18.5 to $25 \mathrm{~kg} / \mathrm{m}^{2}$ were eligible to participate in this study. Subjects who had received tricyclic antidepressants (TCAs), selective serotonin reuptake inhibitors (SSRIs), serotonin-norepinephrine reuptake inhibitors (SNRIs) or monoamine oxidase (MAO) inhibitors and whose 12-lead electrocardiogram indicated a QTc interval $>430 \mathrm{~ms}$, PR interval $>200 \mathrm{~ms}$ or QRS interval $>120 \mathrm{~ms}$ were excluded considering the QT prolongations observed during the single ascending dose study of DA-8031. ${ }^{16}$

\section{Study Design and Procedures}

This study was a dose block-randomized, double-blind, placebo-controlled, multiple ascending dose study with 3 dose groups: 20, 30 and $40 \mathrm{mg}$ of DA-8031. The subjects were randomized to DA-8031 or placebo in a 4:1 ratio in each dose group of 10 subjects and orally administrated once daily for 7 days. The dose escalation was determined after assessing the safety and pharmacokinetic data of the previous dose group. Pharmacokinetic blood samples were collected at 0 (before dosing), 1, 2, 3, 4, 5, 6, 8, 12 and 24 hours after the first dose (Day 1), at pre-dose during multiple doses (Day 2 to Day 6), and 1, 2, 3, 4, 5, $6,8,12,24,36,48,72,96$ and 120 hours at steady state after the last dose (Day 7). For each blood sampling, $6 \mathrm{~mL}$ of blood were collected in heparin and centrifuged at $1981 \mathrm{~g}$ for $10 \mathrm{~min}$ at $4^{\circ} \mathrm{C}$, and three aliquots of supernatant were stored at $-20^{\circ} \mathrm{C}$ until analysis. Plasma 
concentrations of DA-8031 and its metabolites (M1, M2, M4 and M5) were analyzed separately using a validated high-performance liquid chromatography (HPLC)-tandem mass spectrometry (MS/MS) system in the positive ionization mode. ${ }^{16}$

\section{Pharmacokinetic Analysis}

The PK analysis was conducted in subjects who completed the study with quantifiable concentrations of DA-8031 and metabolites. The PK parameters were estimated by noncompartmental methods using WinNonlin ${ }^{\circledR}$ (Pharsight Co, Mountain View, CA, USA) and included maximum plasma concentration $\left(\mathrm{C}_{\max }\right)$, time to reach $\mathrm{C}_{\max }\left(\mathrm{T}_{\max }\right)$, area under the concentration-time curve (AUC) calculated by the linear-up/log-down trapezoidal method, half-life $\left(\mathrm{T}_{1 / 2}\right)$, clearance (CL), accumulation index as the AUC during the dosing interval at steady state divided by the AUC during the dosing interval after the first dose $\left(\mathrm{AUC}_{0-24 \mathrm{~h}, \mathrm{ss}} / \mathrm{AUC}_{0-24 \mathrm{~h}}\right)$, and metabolic ratio (MR) determined by $\mathrm{AUC}_{\text {metabolite }} / \mathrm{AUC}_{\mathrm{DA}-8031}$. These parameters were obtained both after a single dose and at the steady state after multiple doses.

\section{Genetic Analysis}

DMET $^{\mathrm{TM}}$ plus (Affymetrix, Santa Clara, CA, USA) at

DNA Link. Co. Ltd. (Seoul, Korea) was used to conduct the analysis of genes associated with the PK of DA-8031. In total, 225 genes were analyzed which were associated with the enzymes and transporters related to the pharmacokinetics. In this study, five cytochrome-P450 (CYP) enzymes (CYP2C19, CYP2C8, CYP2D6, CYP3A4 and CYP3A5) were selected which are known to be involved in the metabolism of DA-8031 reported in the in vitro study. Based on the genotypes, subjects were classified as follows: for CYP2C19, ultra-rapid metabolizer (UM) $(* 17 / * 17, * 1 / * 17)$, extensive metabolizer (EM) $(* 1 / * 1)$, intermediate metabolizer (IM) $(* 1 / * 2, * 1 / * 3)$ or poor metabolizer $(\mathrm{PM})(* 2 / * 2, * 2 / * 3, * 3 / * 3),{ }^{17}$ and for CYP2D6, ultra-metabolizer (UM) $(* 1 / * 1 \times \mathrm{xN}, * 1 / * 2 \times \mathrm{xN}$, $* 2 / * 2 \mathrm{xN})$, extensive metabolizer (EM) $(* 1 / * 1, * 2 / * 2, * 1 /$ $* 2, * 1 / * 10, * 2 / * 10)$, intermediate metabolizer (IM) $(* 10 /$ $* 10, * 10 / * 41)$ or poor metabolizer (PM) $(* 3 / * 4, * 4 / 44, * 5 /$ $* 5, * 5 / * 6),{ }^{17}$ and for CYP3A4, extensive metabolizer (EM) $(* 1 / * 1)$ or intermediate metabolizer (IM) $(* 1 / * 16$, $* 1 / * 22),{ }^{18,19}$ and for CYP3A5, extensive metabolizer (EM) $(* 1 / * 1)$, intermediate metabolizer (IM) $(* 1 / * 3)$ or poor metabolizer $(\mathrm{PM})(* 3 / * 3){ }^{20}$

\section{Safety and Tolerability Assessments}

The safety and tolerability were evaluated by monitoring adverse events (AEs) by self-reporting and investigators' questionnaire, physical examinations, vital signs, 12-lead electrocardiogram (12-lead ECGs), clinical laboratory test and computerized impedance cardiography (CIC). Twelvelead ECGs were conducted at 0, 1, 2, 3, 4, 6 and 8 hours one day before the first dose (Day -1) as baseline, predose (0), 1, 2, 3, 4, 6 and 8 hours after the first dose (Day 1), pre-dose and 2 hours post-dose during the multiple doses (Day 2 to Day 6), and pre-dose, 1, 2, 3, 4, 6, 8, 24 and 72 hours after the last dose (Day 7). ECG recordings were analyzed for the ventricular rate, PR interval, QT interval and QRS duration, and the heart-rate corrected QT intervals (QTc) were calculated by Bazett's formula $\left(\mathrm{QTcB}=\mathrm{QT} /[\mathrm{RR} \text { interval }]^{1 / 2}\right)$ and Fridericia's formula $\left(\mathrm{QTcF}=\mathrm{QT} /[\mathrm{RR} \text { interval }]^{1 / 3}\right)$.

\section{Statistical Analysis}

SAS $^{\circledR}$ software version 9.4 (SAS Institute Inc., Cary, NC, USA) was used for the statistical analysis. Analysis of variance (ANOVA) and a power model were performed to evaluate the dose proportionality for the $\mathrm{AUC}$ and $\mathrm{C}_{\max }$. To assess the effect of the genetic polymorphisms on PK, dose-normalized $\mathrm{C}_{\max }$ at steady state $\left(\mathrm{C}_{\mathrm{max}, \mathrm{ss}} / \mathrm{D}\right)$ and dosenormalized AUC during the dosing interval at steady state $\left(\mathrm{AUC}_{0-24 \mathrm{~h}, \mathrm{ss}} / \mathrm{D}\right)$ were assumed to have a log-normal distribution. The parameters were evaluated using the generalized linear model with the dose as the covariates, and the geometric mean ratio (GMR) and $90 \%$ confidence interval $(90 \% \mathrm{CI})$ were calculated to assess the difference in the PK parameters between the genotypes. The changes in the maximum QTcB and QTcF intervals from the baseline of each dosage group were compared with the placebo group using ANOVA with Dunnett's $t$-test. Moreover, statistical significance was defined as a $p$-value $<0.05$.

\section{Results}

\section{Study Population}

A total of 32 healthy Korean male subjects were enrolled, and 30 subjects completed the study; Two subjects (each subject in $20 \mathrm{mg}$ and $30 \mathrm{mg}$ ) withdrew their consents after several doses of DA-8031. The PK analysis was conducted in 24 subjects who received DA-8031, and the safety analysis was conducted in 32 subjects who received DA8031 at least once. The age, weight, height, and body mass 


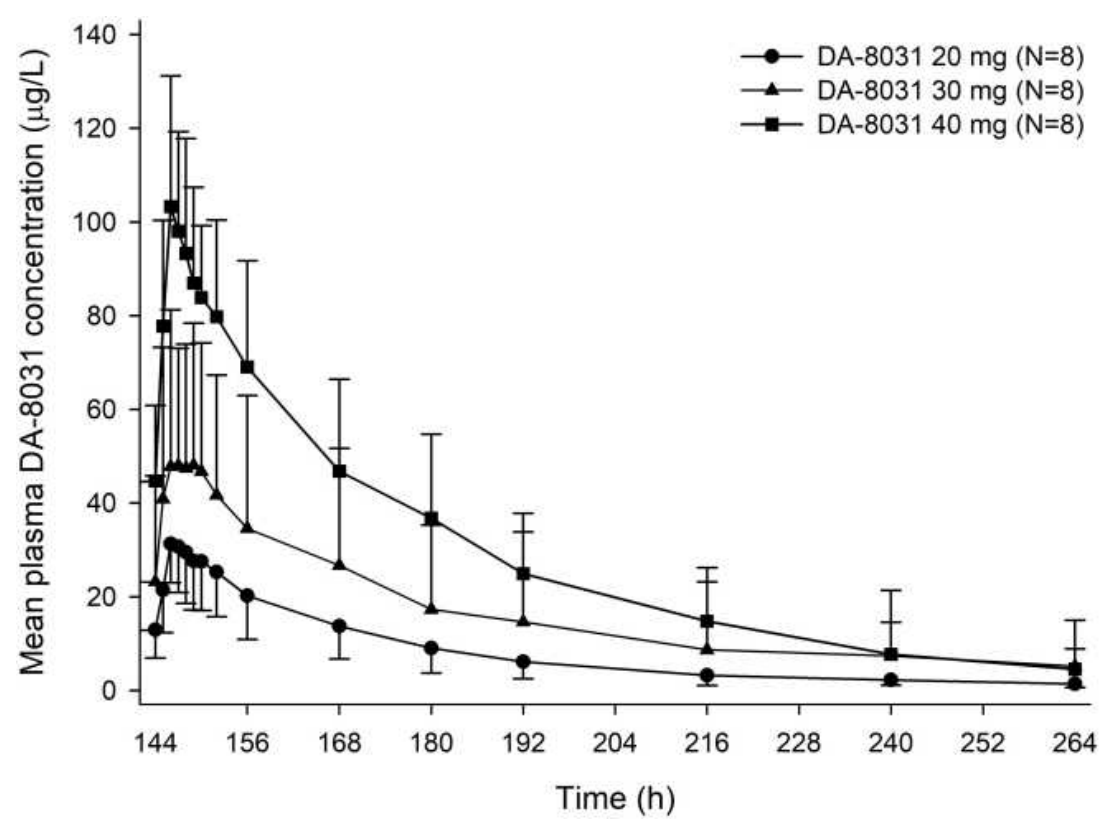

Figure I Mean plasma DA-803I concentration-time profiles at steady state after multiple oral doses of DA-803I 20, 30 or 40 mg. Bars represent standard deviations.

index (BMI) of the 32 enrolled subjects were $26.3 \pm 4.1$ (mean \pm standard deviation) years, $68.9 \pm 4.6 \mathrm{~kg}, 173.8 \pm$ $4.7 \mathrm{~cm}$, and $22.8 \pm 1.6 \mathrm{~kg} / \mathrm{m}^{2}$, respectively.

\section{Pharmacokinetics}

DA-8031 was rapidly absorbed and reached the maximum concentration with a median time of $2-3$ hours at steady

Table I Pharmacokinetic Parameters of DA-803I After a Single or Multiple Oral Doses

\begin{tabular}{|c|c|c|c|c|}
\hline \multirow[t]{2}{*}{ Day } & \multirow[t]{2}{*}{ Parameters } & \multicolumn{3}{|c|}{ Treatment } \\
\hline & & $\begin{array}{l}20 \mathrm{mg} \\
(\mathrm{N}=8)\end{array}$ & $\begin{array}{l}30 \mathrm{mg} \\
(\mathrm{N}=8)\end{array}$ & $\begin{array}{l}40 \mathrm{mg} \\
(\mathrm{N}=8)\end{array}$ \\
\hline \multirow[t]{6}{*}{ Single dose (Day I) } & $T_{\max }(h)^{a}$ & $2.5(1.0-6.0)$ & $2.0(2.0-4.0)$ & $2.0(2.0-6.0)$ \\
\hline & $\mathrm{C}_{\max }(\mu g / L)$ & $18.5 \pm 3.6$ & $29.2 \pm 12.1$ & $49.9 \pm 14.1$ \\
\hline & $\mathrm{AUC}_{0-24 \mathrm{~h}}(\mu \mathrm{g} \cdot \mathrm{h} / \mathrm{L})$ & $219.5 \pm 75.3$ & $353.7 \pm 214.6$ & $608.1 \pm 168.5$ \\
\hline & $A \cup C_{\text {inf }}(\mu g \cdot h / L)$ & $339.3 \pm 142.2$ & $646.4 \pm 728.0$ & $1119.6 \pm 74.9 *$ \\
\hline & $T_{1 / 2}(h)$ & $14.6 \pm 4.0$ & $15.5 \pm 9.7$ & $19.0 \pm 11.5^{*}$ \\
\hline & $\mathrm{CL} / \mathrm{F}(\mathrm{L} / \mathrm{h})$ & $70.9 \pm 36.2$ & $75.8 \pm 38.7$ & $47.3 \pm 21.3^{*}$ \\
\hline \multirow[t]{6}{*}{ Multiple doses (Day 7) } & $T_{\max , s s}(h)^{a}$ & $2.5(2.0-5.0)$ & $2.5(1.0-6.0)$ & $3.0(2.0-5.0)$ \\
\hline & $C_{\max , s s}(\mu g / L)$ & $33.7 \pm 9.8$ & $55.5 \pm 30.7$ & $104.9 \pm 26.8$ \\
\hline & $\mathrm{AUC}_{0-24 h, s s}(\mu \mathrm{g} \cdot \mathrm{h} / \mathrm{L})$ & $504.7 \pm 207.1$ & $872.5 \pm 648.6$ & $1668.9 \pm 493.1$ \\
\hline & $T_{1 / 2, s s}(h)$ & $26.7 \pm 7.2$ & $26.1 \pm 13.6$ & $25.5 \pm 4.4$ \\
\hline & $\mathrm{CL}_{s s} / \mathrm{F}(\mathrm{L} / \mathrm{h})$ & $46.9 \pm 22.4$ & $45.0 \pm 19.8$ & $25.8 \pm 7.7$ \\
\hline & Accumulation index & $2.3 \pm 0.3$ & $2.4 \pm 0.3$ & $2.8 \pm 0.3$ \\
\hline
\end{tabular}

Notes: Values are presented as the mean \pm standard deviation. Accumulation index is calculated as $A \cup C_{0-24 h, s s} / A_{U C} C_{0-24 h} ;{ }^{a} V_{a l u e s}$ are presented as the median (minimummaximum); *N=7, Terminal elimination constants of one subject of the $40 \mathrm{mg}$ dose group were not estimated.

Abbreviations: $\mathrm{AUC}_{0-24 \mathrm{~h}}$, area under the curve from 0 hours to 24 hours; $A \mathrm{AC}_{0-24 \mathrm{~h}, \mathrm{ss}}$, area under the curve from 0 hours to 24 hours at steady state; $A U C_{\text {inf }}$, area under the curve from 0 hours to infinity; $\mathrm{CL} / \mathrm{F}$, total clearance; $\mathrm{CL}_{\text {ss }} / \mathrm{F}$, total clearance at steady state; $\mathrm{C}_{\max }$, maximum concentration; $\mathrm{C}_{\text {max,ss}}$, maximum concentration at steady state; $T_{1 / 2}$, half-life; $T_{1 / 2, s s}$, half-life at steady state; $T_{\max }$, time of $C_{\max } ; T_{\max , s s}$, time of $C_{\max }$ at steady state. 
state after multiple oral doses (Figure 1). The mean $T_{1 / 2}$ ranged from 25.5 to 26.7 hours. The mean apparent clearance of DA-8031 at steady state was 46.9 and $45.0 \mathrm{~L} / \mathrm{h}$ after multiple oral doses of 20 and $30 \mathrm{mg}$, respectively, but decreased to $25.8 \mathrm{~L} / \mathrm{h}$ after multiple doses of $40 \mathrm{mg}$. The mean accumulation indexes were 2.3, 2.4 and 2.8 after multiple oral doses of 20,30 , or $40 \mathrm{mg}$ of DA-8031, respectively (Table 1).

Regarding the analysis of dose proportionality, there were no statistical differences in the dose-normalized $\mathrm{C}_{\mathrm{max}, \mathrm{ss}}$ and $\mathrm{AUC}_{0-24 \mathrm{~h}, \mathrm{ss}}$ among the 20,30 and $40 \mathrm{mg}$ dose groups of DA-8031 assessed by ANOVA $\left(\mathrm{C}_{\mathrm{max}, \mathrm{ss}}\right.$, $\left.p=0.05 ; \mathrm{AUC}_{0-24 \mathrm{~h}, \mathrm{ss}}, p=0.11\right)$. However, the $95 \%$ CIs of the slope of $\mathrm{C}_{\text {max,ss }}$ and $\mathrm{AUC}_{0-24 \mathrm{~h}, \mathrm{ss}}$ in the power model were 1.10-2.13 and 1.08-2.41, respectively.

M4 and M5 were the major metabolites of DA-8031 with a metabolic ratio of $0.19-0.48$ and $0.22-0.46$, respectively (Figure 2A-C). The MR of M4 and M5 at steady state decreased in the $40 \mathrm{mg}$ dose group compared to the 20 or $30 \mathrm{mg}$ dose group (Supplementary Table 1).

\section{Effect of the Genetic Polymorphism on PK}

In this study, there were 16 subjects with CYP2D6 EM, 8 subjects with CYP2D6 IM, and no subjects with CYP2D6 UM or PM. Regarding CYP2C19, there were 11 subjects with EM, 7 subjects with IM, 6 subjects with PM and no subjects with UM (Table 2). The frequency distributions of CYP2D6 and CYP2C19 in this study were similar to those previously known in Koreans from previous reports. ${ }^{21,22}$

The dose-normalized $\mathrm{C}_{\mathrm{max}, \mathrm{ss}}$ of DA-8031 was 1.6-fold higher, and the dose-normalized $\mathrm{AUC}_{0-24 \mathrm{~h}, \mathrm{ss}}$ of DA-8031 was 1.9-fold higher in subjects with CYP2D6 EM than in
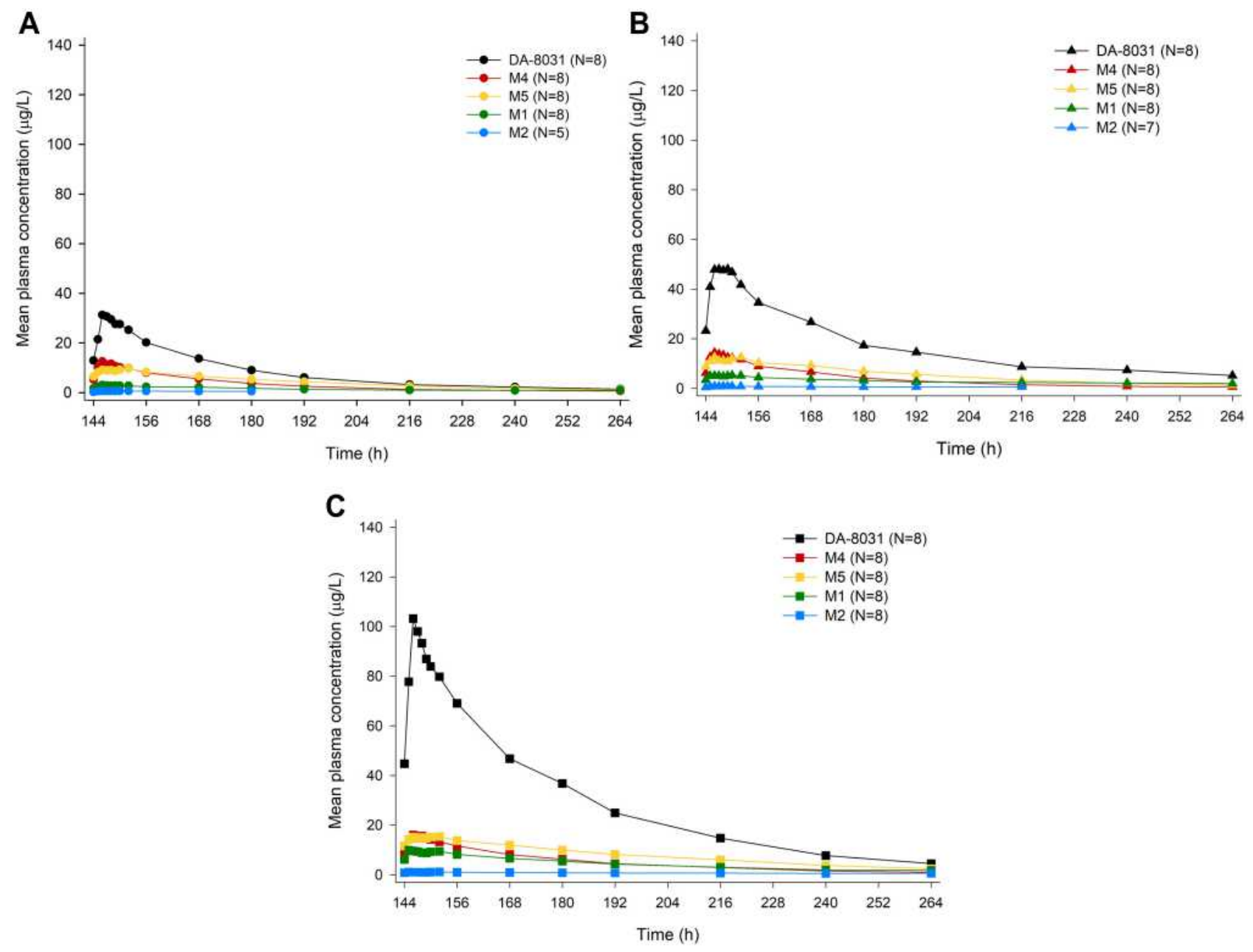

Figure 2 Mean plasma concentration-time profiles of DA-803I and M4, M5, MI, M2 at steady state after multiple oral doses of DA-803। 20,30 or 40 mg. ((A) DA-803। $20 \mathrm{mg}$, (B) DA-8031 $30 \mathrm{mg}$, (C) DA-803। $40 \mathrm{mg}$ ). 
Table 2 Dose-Normalized Pharmacokinetic Parameters of DA-803I at Steady State After Multiple Oral Doses According to the CYP2D6 and CYP2C19 Phenotype

\begin{tabular}{|c|c|c|c|c|c|c|c|c|c|c|}
\hline \multirow[t]{4}{*}{ Parameters } & \multicolumn{4}{|l|}{ CYP2D6 } & \multicolumn{6}{|l|}{ CYP2C19 } \\
\hline & \multirow{3}{*}{$\begin{array}{l}\text { EM } \\
(N=16) \\
\text { Mean } \pm S D\end{array}$} & \multirow{3}{*}{$\begin{array}{l}\text { IM } \\
(\mathrm{N}=8) \\
\text { Mean } \pm \mathrm{SD}\end{array}$} & \multirow{3}{*}{$\begin{array}{l}\text { GMR for } \\
\text { IM to EM } \\
(90 \% \mathrm{Cl})\end{array}$} & \multirow{3}{*}{$\begin{array}{l}P \text { - } \\
\text { value }\end{array}$} & \multirow{2}{*}{$\begin{array}{l}E M \\
(N=I I)\end{array}$} & \multirow{2}{*}{$\frac{I M}{(N=7)}$} & \multirow{3}{*}{$\begin{array}{l}\text { GMR for } \\
\text { IM to EM } \\
(90 \% \mathrm{Cl})\end{array}$} & PM & \multirow{3}{*}{$\begin{array}{l}\text { GMR for } \\
\text { PM to EM } \\
(90 \% \mathrm{Cl})\end{array}$} & \multirow[t]{3}{*}{$P$-value } \\
\hline & & & & & & & & $(\mathrm{N}=6)$ & & \\
\hline & & & & & Mean \pm SD & Mean \pm SD & & Mean \pm SD & & \\
\hline$C_{\text {max,ss }} /$ Dose & $1.66 \pm 0.48$ & $2.84 \pm 0.87$ & $\begin{array}{l}1.65 \\
(1.38-1.98)\end{array}$ & $<0.0001$ & $2.05 \pm 0.57$ & $2.26 \pm 1.28$ & $\begin{array}{l}1.02 \\
(0.72-1.45)\end{array}$ & $1.81 \pm 0.71$ & $\begin{array}{l}1.00 \\
(0.67-1.47)\end{array}$ & 0.9917 \\
\hline $\begin{array}{l}\text { AUC }_{0-24 \mathrm{~h}, \mathrm{ss}} / \\
\text { Dose }\end{array}$ & $23.94 \pm 8.29$ & $48.16 \pm 17.39$ & $\begin{array}{l}1.94 \\
(1.54-2.44)\end{array}$ & $<0.0001$ & $31.57 \pm 9.12$ & $36.61 \pm 26.23$ & $\begin{array}{l}1.00 \\
(0.63-1.58)\end{array}$ & $27.47 \pm 14.45$ & $\begin{array}{l}0.96 \\
(0.57-1.60)\end{array}$ & 0.9827 \\
\hline MR of M4 & $0.46 \pm 0.26$ & $0.15 \pm 0.08$ & $\begin{array}{l}0.33 \\
(0.2 I-0.5 I)\end{array}$ & 0.0004 & $0.26 \pm 0.11$ & $0.35 \pm 0.27$ & $\begin{array}{l}0.87 \\
(0.39-1.95)\end{array}$ & $0.55 \pm 0.35$ & $\begin{array}{l}I .5 I \\
(0.6 I-3.7 I)\end{array}$ & 0.5035 \\
\hline MR of M5 & $0.46 \pm 0.20$ & $0.18 \pm 0.11$ & $\begin{array}{l}0.33 \\
(0.20-0.56)\end{array}$ & 0.0016 & $0.34 \pm 0.16$ & $0.39 \pm 0.32$ & $\begin{array}{l}0.66 \\
(0.27-1.59)\end{array}$ & $0.39 \pm 0.21$ & $\begin{array}{l}0.85 \\
(0.32-2.27)\end{array}$ & 0.6286 \\
\hline MR of MI & $0.11 \pm 0.02$ & $0.13 \pm 0.02$ & $\begin{array}{l}1.13 \\
(0.95-1.34)\end{array}$ & 0.2236 & $0.13 \pm 0.02$ & $0.12 \pm 0.01$ & $\begin{array}{l}0.98 \\
(0.82-1.17)\end{array}$ & $0.09 \pm 0.02$ & $\begin{array}{l}0.69 \\
(0.57-0.85)\end{array}$ & 0.0032 \\
\hline$M R$ of $M 2$ & $0.026 \pm 0.009$ & $0.015 \pm 0.006$ & $\begin{array}{l}0.59 \\
(0.46-0.77)\end{array}$ & 0.0024 & $0.022 \pm 0.010$ & $0.024 \pm 0.013$ & $\begin{array}{l}0.96 \\
(0.61-1.52)\end{array}$ & $0.023 \pm 0.006$ & $\begin{array}{l}0.91 \\
(0.55-1.52)\end{array}$ & 0.9281 \\
\hline
\end{tabular}

Note: Values are represented as the mean \pm standard deviations.

Abbreviations: $\mathrm{AUC}_{0-24 h, s s}$, area under the curve from 0 hours to 24 hours at steady state; $\mathrm{Cl}$, confidence interval; $\mathrm{C}_{\text {max,ss}}$, maximum concentration at steady state; $\mathrm{EM}$, extensive metabolizer; GMR, geometric mean ratio; IM, intermediate metabolizer; MR, metabolic ratio; PM, poor metabolizer.

those with CYP2D6 IM (Figure 3A and B and Table 2). The MRs of M4, M5 and M2 showed significant differences according to the CYP2D6 phenotype (Table 2). On the other hand, the PK of DA-8031 did not significantly differ according to the CYP2C19 phenotype (Figure 3C and D), and the polymorphisms of CYP3A4 and CYP3A5 did not have any effect on the PK of DA-8031 (data not shown). All the subjects had the same genotype for CYP2C8; thus, the analysis of CYP2C8 was not conducted.

\section{Safety and Tolerability}

A total of 32 AEs was reported in 15 (46.9\%) of the 32 subjects (Table 3). Seven AEs occurred in 6 placebo subjects, and 25 AEs occurred in 26 DA-8031 subjects (Table 3). Among the 25 AEs, 18 AEs in 9 subjects were assessed to be related to DA-8031. The most frequently reported AEs related to DA-8031 was nausea (4 cases) followed by electrocardiogram QT prolongation (3 cases). There were no serious AEs, and all AEs were mild. All subjects recovered without sequelae, and there were no significant trends in the frequency of the AEs with the ascending doses.

The mean QTcB and QTcF interval did not over 450 msec (Figure 4A and B). The prolongation of QTcB interval over $450 \mathrm{msec}$ was observed in 1 subject in the $20 \mathrm{mg}$ dose group, 2 subjects in the $30 \mathrm{mg}$ dose group and 1 subject in the $40 \mathrm{mg}$ dose group and not in the placebo. The QTcB interval prolongation of the subject in $20 \mathrm{mg}$ dose group was observed at 2 hours after 3 multiple doses (Day 3) and was evaluated to not be associated with DA- 8031 because of a lack of rest before recording the 12-lead ECGs and immediately disappearing. Two subjects in the $30 \mathrm{mg}$ dose group and 1 subject in the $40 \mathrm{mg}$ dose group were observed at 0-4 hours after 5-7 multiple doses (Day 5-7). Their QTcB interval decreased below $450 \mathrm{msec}$ at least 2 hours after the prolongation. In the case of using Fridericia's formula, the prolongation of the QTcF intervals over $450 \mathrm{msec}$ was observed in 2 subjects in the $30 \mathrm{mg}$ dose group at 2-4 hours after the last dose of the multiple doses (Day 7) and decreased below $450 \mathrm{msec}$ at 6 hours post-dose. The maximum changes in the QTcB and QTcF intervals after multiple doses from baseline were significantly different between the $30 \mathrm{mg}$ and $40 \mathrm{mg}$ dose groups and placebo (QTcB interval: $p=$ 0.004, $p<0.001$; QTcF interval: $p=0.003, p=0.001$ ). However, no clinical symptoms related to the prolongation of the QTc interval were observed. No clinically significant changes were reported in the physical examination, computerized impedance cardiography (CIC), and clinical laboratory test. 

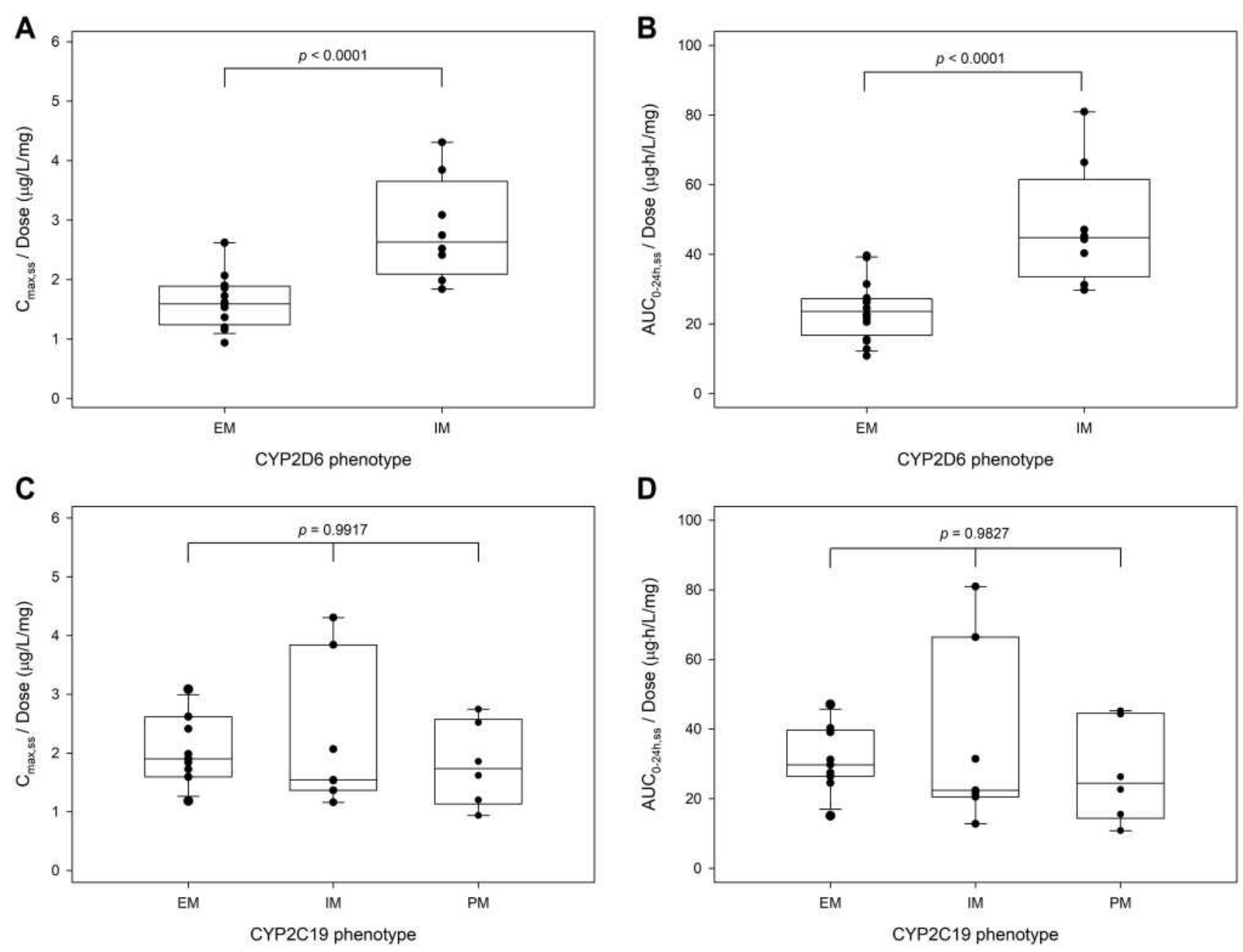

Figure 3 Dose-normalized $C_{\max }$ and $A \cup C_{\text {last }}$ of DA-803I at steady state after multiple oral doses according to the CYP2D6 and CYP2CI9 phenotype. (Dose-normalized (A) $C_{\max },(B) A \cup C_{0-24 h},(C) C_{\max , s s},(D) A \cup C_{0-24 h, s s}$.

\section{Discussions}

The pharmacokinetics of DA-8031 after multiple doses were similar to those after a single dose, and the systemic exposure showed non-linearity with the increasing doses. The accumulation index ranged from 2.3 to 2.8 which were similar to the expected values based on the PK after a single ascending dose. ${ }^{16}$

About the dose proportionality, at steady state, although the dose-normalized $\mathrm{C}_{\mathrm{max}, \mathrm{ss}}$ and $\mathrm{AUC}_{0-24 \mathrm{~h}, \mathrm{ss}}$ were not significantly different between the dose groups, the $95 \%$ CIs of the slope of the PK parameters in the power model did not include 1. Overall, the systemic exposure increased more than dose-proportionally with the increasing doses after multiple oral administrations with a dose range of 20-40 mg. Likewise, the apparent clearance of DA-8031 and the MR of the metabolites at steady state decreased in the $40 \mathrm{mg}$ dose group, but not $\mathrm{T}_{1 / 2}$. This phenomenon might be caused by the saturation of first-pass metabolism which was also observed in other SSRIs such as paroxetine and/or by the saturation of the P-glycoprotein (P-gp) transporter in the gastrointestinal track associated with the absorption of DA-8031. ${ }^{23-25}$

The genetic polymorphism of CYP2D6 and CYP2C19 can influence the metabolism of SSRIs, affecting interindividual differences in PK parameters and eventually affecting the drug efficacy and safety. ${ }^{17}$ These polymorphisms also had an impact on the metabolism of DA- 8031 . The systemic exposure of DA-8031 was significantly lower in subjects with CY2D6 EM than in those with CYP2D6 IM after multiple oral doses of DA-8031. The metabolic ratio of M4, M5 and M2 were significantly higher in subjects with CY2D6 EM than in those with CYP2D6 IM. However, the effect of genetic polymorphism on the metabolism to M1 and M2 were not obvious 
Table 3 Summary of Adverse Events (AEs) After Multiple Oral Doses of DA-803।

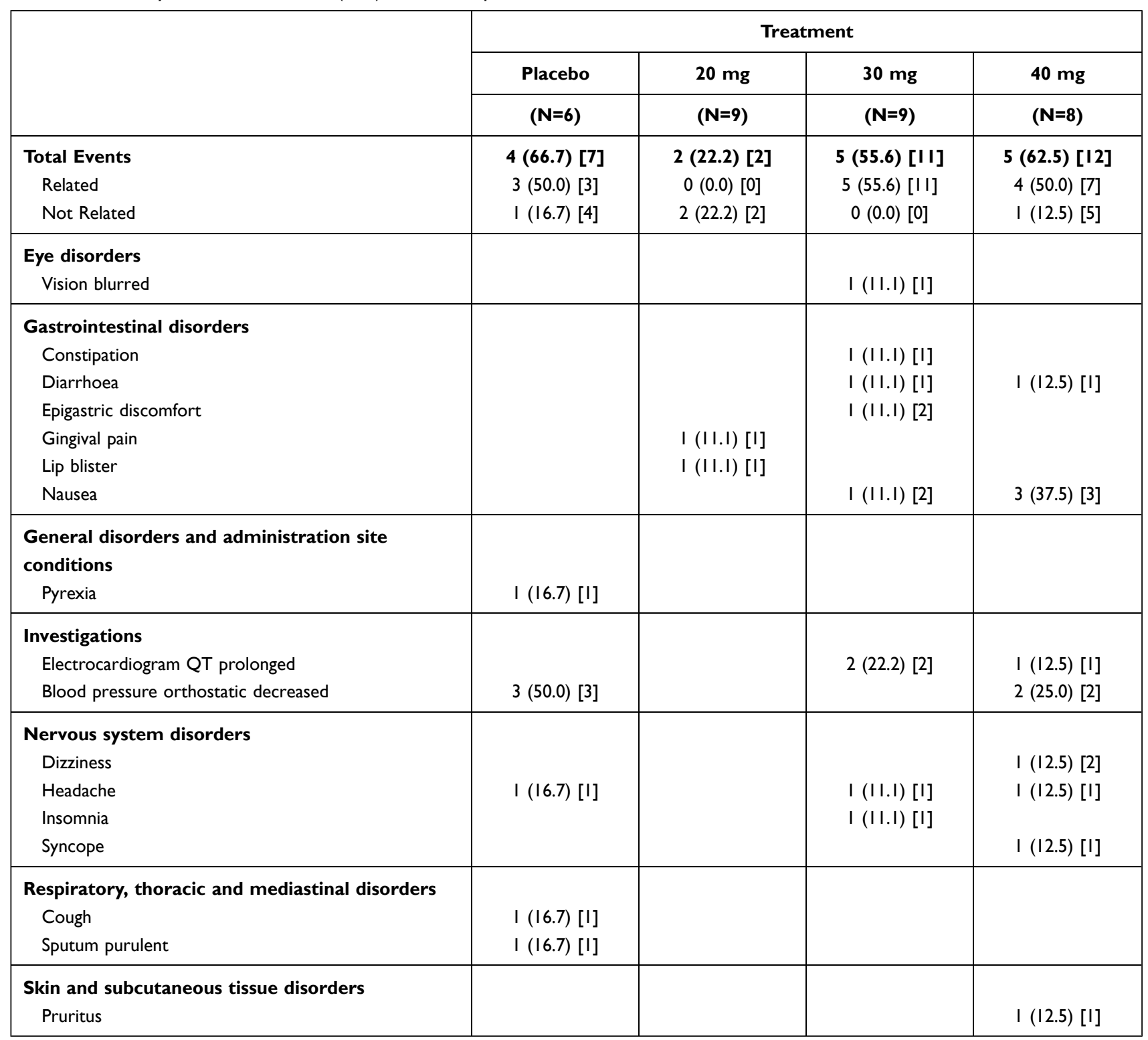

Notes: AEs are categorized by systemic organ class (SOC) and preferred term (PT); Values are presented as number of subjects (percentage of subjects) [number of events].

because of the low concentration and MR. In summary, the results of a previous and this study support that DA-8031 is metabolized to M4 and sequentially to M5 by CYP2D6 and to M2 and M1 by CYP2D6 or CYP2C19 with a limited proportion, also observed in the nonclinical study. However, there were no CYP2D6 UM and PM in this study. Therefore, additional pharmacogenetic assessments may be considered in a larger number of subjects.

Based on the assessments of safety and tolerability, the most commonly observed AEs were consistent with the previously reported AEs of SSRIs. ${ }^{13}$ The risk of QT prolongation with SSRIs has recently become an important consideration for the selection of SSRIs. ${ }^{26-29}$ Moreover, in the case of DA-8031, the preclinical and first-in-human single ascending dose study showed that DA-8031 induced $h E R G$ current inhibition and QT prolongation. ${ }^{16}$ In the single ascending dose study, 6 of the 8 subjects receiving a $120 \mathrm{mg}$ dose showed QTc intervals longer than 450 msec. ${ }^{16}$ In this multiple ascending dose study, the QT intervals increased after multiple doses of 30 and $40 \mathrm{mg}$ of DA-8031 compared to those of the placebo. In addition, the QT prolongation grade 1 referring to CTCAE version 5.0 was observed in all dose groups. ${ }^{30}$ However, the prolongation of the QTcB 

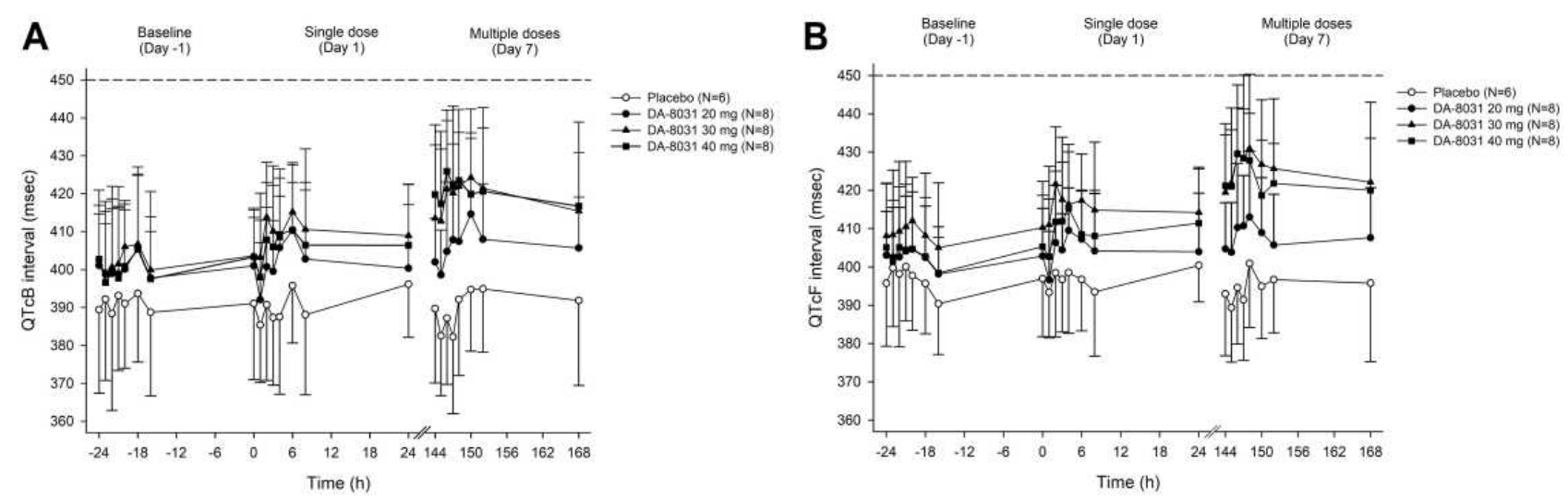

Figure 4 Mean (A) QTcB and (B) QTcF interval-time profiles before and after a single or multiple oral doses of placebo or DA-803। 20 , 30 or 40 mg. Bars represent standard deviations.

interval of 1 subject in the $20 \mathrm{mg}$ dose group seems to be not associated with DA-8031. And despite the QT prolongation, the prolongations were not over $500 \mathrm{msec}$ and disappeared 2 hours after the observation, and none of the subjects showed any clinical symptoms. Consequently, although there is little concern about QT prolongation within the dose range of $20-40 \mathrm{mg}$, further assessment of cardiac safety including the QT prolongation of DA-8031 needs to be considered in patients with PE.

\section{Conclusion}

DA-8031 showed more than the dose-proportional increase of systemic exposure, and the systemic exposure of DA-8031 was affected by the genetic polymorphisms of CYP2D6. DA-8031 was well tolerated in the dose range of 20-40 mg after multiple doses over 7 days despite the mild QT prolongations observed.

\section{Data Sharing Statement}

The individual de-identified participant data that supporting the results in this study are available from the corresponding author (leejh413@snu.ac.kr) or sponsor on a reasonable request.

\section{Acknowledgments}

This study was sponsored by Dong-A ST, Seoul, Korea. The investigation was conducted at the Clinical Trials Center, Seoul National University Hospital.

\section{Disclosure}

All authors report no conflicts of interest regarding the publication of this manuscript.

\section{References}

1. Althof SE, McMahon CG, Waldinger MD, et al. An update of the international society of sexual medicine's guidelines for the diagnosis and treatment of premature ejaculation (PE). Sex Med. 2014;2 (2):60-90. doi:10.1002/sm2.28

2. Ahn TY, Park JK, Lee SW, et al. Prevalence and risk factors for erectile dysfunction in Korean men: results of an epidemiological study. $J$ Sex Med. 2007;4(5):1269-1276. doi:10.1111/j.17436109.2007.00554.x

3. Ceglia I, Acconcia S, Fracasso C, Colovic M, Caccia S, Invernizzi RW. Effects of chronic treatment with escitalopram or citalopram on extracellular 5-HT in the prefrontal cortex of rats: role of 5-HT1A receptors. Br J Pharmacol. 2004;142(3):469-478. doi:10.1038/sj.bjp. 0705800

4. Giuliano F, Clement P. Serotonin and premature ejaculation: from physiology to patient management. Eur Urol. 2006;50(3):454-466. doi:10.1016/j.eururo.2006.05.055

5. Demir Y, Balci N, Gurbuz M. Differential effects of selective serotonin reuptake inhibitors on paraoxonase-1 enzyme activity: an in vitro study. Comp Biochem Physiol C Toxicol Pharmacol. 2019;226:108608. doi:10.1016/j.cbpc.2019.108608

6. Ozaslan MS, Balci N, Demir Y, Gurbuz M, Kufrevioglu OI. Inhibition effects of some antidepressant drugs on pentose phosphate pathway enzymes. Environ Toxicol Pharmacol. 2019;72:103244. doi:10.1016/j.etap.2019.103244

7. F Lasker G, Halis F, Gokce A. Selective serotonin reuptake inhibitors for premature ejaculation: review of erectile and ejaculatory side effects. Curr Drug Saf. 2014;9(2):118-126. doi:10.2174/ 1574886309666140120095846

8. McMahon C, Kim SW, Park NC, et al. Treatment of premature ejaculation in the Asia-Pacific region: results from a Phase III double-blind, parallel-group study of dapoxetine. J Sex Med. 2010;7 (1 Pt 1):256-268. doi:10.1111/j.1743-6109.2009.01560.x

9. Mirone V, Arcaniolo D, Rivas D, et al. Results from a prospective observational study of men with premature ejaculation treated with dapoxetine or alternative care: the PAUSE study. Eur Urol. 2014;65 (4):733-739. doi:10.1016/j.eururo.2013.08.018

10. Buvat J, Tesfaye F, Rothman M, Rivas DA, Giuliano F. Dapoxetine for the treatment of premature ejaculation: results from a randomized, double-blind, placebo-controlled Phase 3 trial in 22 countries. Eur Urol. 2009;55(4):957-967. doi:10.1016/j.eururo.2009.01.025

11. Waldinger MD. Treatment of premature ejaculation with selective serotonin re-uptake inhibitors. In: Premature Ejaculation. Milano: Springer; 2013:229-240. 
12. Waldinger MD, Schweitzer DH, Olivier B. On-demand SSRI treatment of premature ejaculation: pharmacodynamic limitations for relevant ejaculation delay and consequent solutions. J Sex Med. 2005;2(1):121-131. doi:10.1111/j.1743-6109.2005.20112.x

13. Ferguson JM. SSRI antidepressant medications; Adverse effects and tolerability. Prim Care Companion J Clin Psychiatry. 2001;3 (1):22-27. doi:10.4088/pcc.v03n0105

14. Sahan A, Cubuk A, Ozkaptan O, et al. Comparison of the safety and efficacy of the on-demand use of sertraline, dapoxetine, and daily use of sertraline in the treatment of patients with lifelong premature ejaculation: a prospective randomised study. Andrologia. 2020;52 (11):e13854. doi:10.1111/and.13854

15. Kang KK, Sung JH, Kim SH, Lee S. Effect of DA-8031, a novel oral compound for premature ejaculation, on male rat sexual behavior. Int J Urol. 2014;21(3):325-329. doi:10.1111/iju.12256

16. Shin D, Lee S, Yi S, et al. Pharmacokinetics and tolerability of DA-8031, a novel selective serotonin reuptake inhibitor for premature ejaculation in healthy male subjects. Drug Des Devel Ther. 2017;11:713-723. doi:10.2147/DDDT.S126861

17. Hicks JK, Bishop JR, Sangkuhl K, et al. Clinical pharmacogenetics implementation consortium (CPIC) guideline for CYP2D6 and CYP2C19 genotypes and dosing of selective serotonin reuptake inhibitors. Clin Pharmacol Ther. 2015;98(2):127-134. doi:10.1002/ cpt. 147

18. Pharmacogene Variation Consortium. CYP3A4 allele nomenclature; Available from: https://www.pharmvar.org/gene/CYP3A4. Accessed May 11, 2021.

19. Maekawa K, Yoshimura T, Saito Y, et al. Functional characterization of CYP3A4.16: catalytic activities toward midazolam and carbamazepine. Xenobiotica. 2009;39(2):140-147. doi:10.1080/ 00498250802617746

20. Birdwell KA, Decker B, Barbarino JM, et al. Clinical pharmacogenetics implementation consortium (CPIC) guidelines for CYP3A5 Genotype and tacrolimus dosing. Clin Pharmacol Ther. 2015;98 (1):19-24. doi:10.1002/cpt.113

21. Byeon JY, Kim YH, Lee CM, et al. CYP2D6 allele frequencies in Korean population, comparison with East Asian, Caucasian and African populations, and the comparison of metabolic activity of CYP2D6 genotypes. Arch Pharm Res. 2018;41(9):921-930. doi:10.1007/s12272-018-1075-6
22. Dorji PW, Tshering G, Na-Bangchang K. CYP2C9, CYP2C19, CYP2D6 and CYP3A5 polymorphisms in South-East and East Asian populations: a systematic review. J Clin Pharm Ther. 2019;44(4):508-524. doi:10.1111/jcpt.12835

23. Alhadab AA, Brundage RC. Population pharmacokinetics of sertraline in healthy subjects: a model-based meta-analysis. AAPS J. 2020;22(4):73. doi:10.1208/s12248-020-00455-y

24. Hiemke C. Paroxetine: pharmacokinetics and pharmacodynamics. Fortschr Neurol Psychiatr. 1994;62(Suppl 1):2-8. doi:10.1055/ s-2007-1002354

25. Uno T, Akamine Y, Yasui-Furukori N, Hirano T. Effects of selective serotonin reuptake inhibitors on the pharmacokinetics of proton pump inhibitors. Neuropsychiatry. 2017;7(4).

26. Funk KA, Bostwick JR. A comparison of the risk of QT prolongation among SSRIs. Ann Pharmacother. 2013;47(10):1330-1341. doi:10.1177/1060028013501994

27. U.S. Food and Drug Administration. FDA drug safety communication: abnormal heart rhythms associated with high doses of Celexa (citalopram hydrobromide); 2017. Available from: https:/www.fda. gov/drugs/drug-safety-and-availability/fda-drug-safety-communica tion-revised-recommendations-celexa-citalopram-hydrobromiderelated. Accessed November 18, 2021.

28. Maljuric NM, Noordam R, Aarts N, et al. Use of selective serotonin re-uptake inhibitors and the heart rate corrected QT interval in a real-life setting: the population-based Rotterdam Study. $\mathrm{Br} J$ Clin Pharmacol. 2015;80(4):698-705. doi:10.1111/bcp.12681

29. Beach SR, Kostis WJ, Celano CM, et al. Meta-analysis of selective serotonin reuptake inhibitor-associated QTc prolongation. J Clin Psychiatry. 2014;75(5):e441-e449. doi:10.4088/JCP.13r08672

30. U.S. Department of Health and Human Services. Common terminology criteria for adverse events (CTCAE) ver 5.0. 2017. Available from: https://ctep.cancer.gov/protocoldevelopment/electronic_applica tions/ctc.htm\#ctc_50. Accessed November 18, 2021.

\section{Publish your work in this journal}

Drug Design, Development and Therapy is an international, peerreviewed open-access journal that spans the spectrum of drug design and development through to clinical applications. Clinical outcomes, patient safety, and programs for the development and effective, safe, and sustained use of medicines are a feature of the journal, which has also been accepted for indexing on PubMed Central. The manuscript management system is completely online and includes a very quick and fair peer-review system, which is all easy to use. Visit http://www. dovepress.com/testimonials.php to read real quotes from published authors. 